\title{
Adaption and validation of the adherence barriers questionnaire for HIV patients on antiretroviral therapy (ABQ-HIV)
}

\author{
Sabrina Mueller ${ }^{1}$, Thomas Wilke ${ }^{1 *}$, Vanessa Gorasso ${ }^{1}$, Marc Erhart ${ }^{2}$ and Jens M. Kittner ${ }^{2,3}$
}

\begin{abstract}
Background: Despite substantial advances in antiretroviral therapy (ART) for human immunodeficiency virus (HIV) in the last decades, non-adherence (NA) continues to be a major challenge in the real-life treatment. To meet this challenge, adherence-promoting interventions with a tailored approach towards patient-specific adherence barriers that are identified using a reliable and practicable questionnaire are needed. The aim of this investigation was to develop and validate a respective questionnaire (Adherence Barriers Questionnaire for HIV: ABQ-HIV), based on an earlier version of the $\mathrm{ABQ}$.
\end{abstract}

Methods: The existing ABQ was discussed by an expert panel and revised according to the specifications of ART therapy for HIV patients. Initially, the ABQ-HIV consisted of 17 items formulated as statements (4-point-Likert-scale ranging from "strongly agree" to "strongly disagree"). A higher score indicates a higher influence of a certain barrier on patient's perceptions. The ABQ-HIV was applied in a cross-sectional survey of German HIV patients. Evaluation of the questionnaire included an assessment of internal consistency as well as factor analysis. Convergent validity was assessed by comparing the ABQ-HIV score with the degree of self-reported adherence measured by the 8-item Morisky Medication Adherence Scale (MMAS-80).

Results: Three hundred seventy patients were able to be included in all validation analyses. The included patients had a mean age of 51.2 years, and $15.7 \%$ were female. The mean HIV infection time was 11.7 years, and the mean duration of treatment since first starting ART was 8.7 years.

Twenty-five patients - excluded from all further analyses - were not able/willing to answer all ABQ-HIV questions. The results of the reliability analysis showed a Cronbach's a of 0.708 for the initial 17-items in the ABQ-HIV draft. Two items were eliminated from the initial questionnaire, resulting in a Cronbach's a of 0.720 and a split-half reliability of 0.724 (Spearman-Brown coefficient).

Based on the reduced 15-item scale, the factor analysis resulted in three different components of the questionnaire. Component 1, with seven items, represents the unintentional adherence barriers. The second component, which contains five items, can be labelled as a subscale describing barriers associated with disease/treatment knowledge. Finally, three items, which can be summarized as intentional adherence barriers, show maximum loading in the third component.

The score of the reduced 15-item ABQ-HIV scale, as well as the scores of the three subscales, correlated significantly with the MMAS score. All correlation coefficients were negative, indicating that higher burdens of adherence barriers measured by ABQ-HIV or its subscales were associated with a lower MMAS score and thus, with a lower adherence level.

The ROC analysis using the MMAS low adherence classification as its state variable provided a cut-off for the ABQ-HIV (Continued on next page)

\footnotetext{
* Correspondence: thomas.wilke@ingress-health.com

${ }^{1}$ Ingress-Health HWM GmbH, Wismar, Germany

Full list of author information is available at the end of the article
}

(c) The Author(s). 2018 Open Access This article is distributed under the terms of the Creative Commons Attribution 4.0 International License (http://creativecommons.org/licenses/by/4.0/), which permits unrestricted use, distribution, and reproduction in any medium, provided you give appropriate credit to the original author(s) and the source, provide a link to the Creative Commons license, and indicate if changes were made. The Creative Commons Public Domain Dedication waiver (http://creativecommons.org/publicdomain/zero/1.0/) applies to the data made available in this article, unless otherwise stated. 


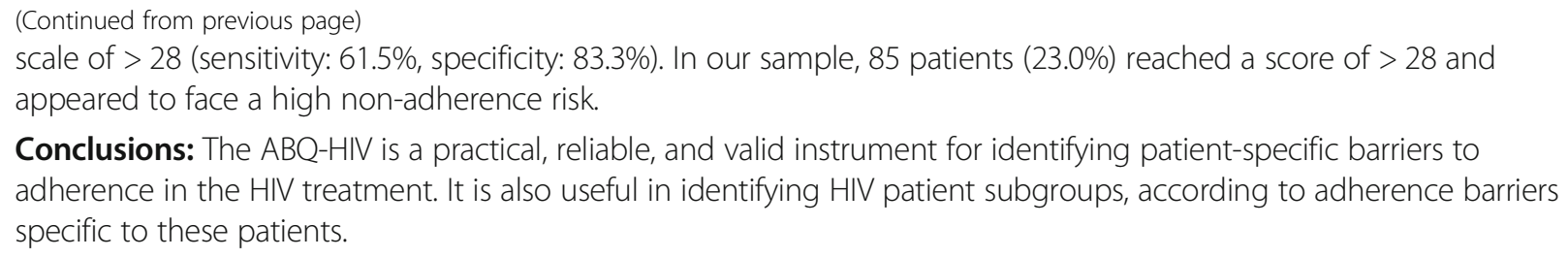

Conclusions: The ABQ-HIV is a practical, reliable, and valid instrument for identifying patient-specific barriers to adherence in the HIV treatment. It is also useful in identifying HIV patient subgroups, according to adherence barriers specific to these patients.

Keywords: Adherence, Non-adherence, Adherence barriers, Human immunodeficiency virus (HIV), Antiretroviral therapy (ART), Adherence barriers questionnaire (ABQ), Patient questionnaire

\section{Background}

Medication adherence, which can be defined as the extent to which a patient's medicine-taking behavior corresponds with agreed instructions from a health care provider [13 ], is essential for realizing the potential benefits of most medication-based treatment [1-4]. Many patients, especially those with chronic diseases, experience difficulties in adhering to a recommended treatment plan. Medication non-adherence (NA), with average rates of those affected being between 30 and $50 \%$, is a major challenge in the real-life treatment of these patients $[3,4]$.

Despite several advances in antiretroviral therapy (ART) for human immunodeficiency virus (HIV) in the last decades [5], non-adherence (NA) continues to be a critical phenomenon in the treatment of these patients. Lacking adequate adherence, sufficient concentrations of antiretroviral agents to suppress HIV replication are not maintained in infected cells. Not only short-term virological response will be poor, but low drug concentrations also dramatically accelerate development of drug-resistance [6]. Therefore, strict adherence to ART is essential for treatment success $[7,8]$.

Several interventions to ensure and support adherence to ART have been tested, but results across several studies indicated a lack of efficacy so far [9]. One major reason may be the failure to successfully customize adherence interventions to patient-specific needs or preferences [3]: Existing research shows that the qualitative and quantitative contribution of a variety of different factors (adherence barriers) is vastly different for most patients [9].

In line with this, the World Health Organization (WHO) described NA as being a complex and multidimensional construct, which is related to socio-economic, health care system-related, disease- and therapy-specific as well as patient-related factors [10]. Therefore, recent research proposes to differentiate different types of NA, especially between intentional and unintentional NA [3, 11-13].

In order to differentially assess adherence barriers, a reliable and valid instrument to identify causes of NA in HIV patients is also needed. The "Adherence Barriers
Questionnaire" (ABQ) has already been shown to be practical, reliable, and valid in chronic indications with self-administrated medication [14]. Therefore, the aim of the current study was to adapt and validate the ABQ to the specific needs of HIV patients.

\section{Methods}

The previously developed ABQ was used as a basis. By reviewing the literature, it was found that no similar patient-report outcome measure addressing barriers of adherence in the implementation of ART therapy in HIV had been previously published. Initial adaptation of the ABQ was thoroughly discussed with an expert panel and was based on existing evidence on potential causes of NA in HIV patients. The panel included clinicians with several years of specific experience, as well as the developer of the original ABQ (first author of this manuscript). The ABQ research team assessed the suitability of the existing items and added additional items that were identified to be relevant in the HIV indication based on the results of the conducted literature review. Clinical experts were asked to evaluate the generated item collection with respect to their relevance and to add important features that could possibly affect patients' adherence to medication which were not covered so far. After that, the drafted ABQ-HIV passed two revision rounds.

To evaluate the psychometric properties of the generated $\mathrm{ABQ}-\mathrm{HIV}$, a cross-sectional, non-interventional study of a cohort of HIV patients in southwest Germany was conducted. Nine outpatient specialists for infectious diseases consecutively included patients aged above 18 years with a confirmed diagnosis of HIV. Patients were eligible if they had been treated with ART for at least 1 year. A written informed consent was obtained from each patient before inclusion in the study.

Each participant was asked to answer a written questionnaire containing the ABQ-HIV (Additional file 1) as well as the Morisky Medication Adherence Scale (MMAS-8@), which had been translated into German. The MMAS is a validated and broadly used self-report instrument, which, containing 8 items, measures a specific medication-taking behavior. This instrument had 
already been used for HIV patients [15-19]. The overall MMAS score ranges from 0 to 8 , with a higher score indicating better adherence. Based on the score, adherence levels can be categorized as high, medium, and low.

In addition, relevant patient characteristics and treatment-related information were collected by the study sites, using a pre-defined case report form.

The utility of the ABQ-HIV was evaluated as follows: Firstly, the properties of the separate items were assessed. This includes the examination of missing data, which provides information about the clarity of the questions. Items with a disproportionate share of missing data indicate an overstraining of the respondent regarding understanding or sensibility. Furthermore, floor and ceiling effects were assed for each item, and items with a high endorsement rate for one answer option were discussed to be excluded from the questionnaire, as these items are considered to be redundant because they add little value to the index $[20,21]$. Secondly, internal reliability was evaluated by calculating Cronbach's $\alpha$; with a currently acceptable value of $0.7-0.9[20,22]$. This also included an assessment of whether exclusion of a respective item would lead to a considerable improvement of the value of Cronbach's $\alpha$. Furthermore, split-half reliability was assessed based on the Spearman-Brown Formula, where the SpearmanBrown coefficient $\geq 0.7$ was considered satisfactory [23]. Item-total correlation with an acceptable value between $0.2-0.8$ [15] was also examined. Thirdly, after final decision about exclusion of items based on the evaluation of item-properties and reliability, a factor analysis with varimax rotation was used to identify potential subscales of the ABQ-HIV. Items that showed maximum loading on the same factor were considered to belong to one subscale. Fourthly, the convergent validity, which refers to the degree to which two measures that theoretically should be related are in fact related to each other, was examined in this study. Here, correlation between the self-reported adherence of each patient measured by the MMAS and the ABQ-HIV score was investigated. Furthermore, the MMAS was used to identify a meaningful threshold of the ABQ-HIV by means of receiver operating characteristic (ROC) analysis.

The study was approved by the independent Ethics Commissions of Rhineland-Palatinate (837.077.16 (10396)), Hessia (121/2016), and Saarland (132/16), Germany.

\section{Results}

After the above outlined expert panel discussion, the drafted ABQ-HIV used for the quantitative patient survey contained 17 items. Each item was formulated as a statement. The response structure of the original ABQ was kept. This rating scale was chosen by assessing the grade of information exploitation and, on the other hand, the risk of overtaxing respondents. Finally, a 4-point Likert scale was defined, which deliberately left out a mean response option, to force the respondents to a decision. The possible answers were "strongly agree", "generally agree", "generally disagree" and "strongly disagree", which were given values from 1 to 4 , or rather 4 to 1 , depending on the formulation of each item (a higher score indicated a higher influence of a certain barrier on a patient's perceptions); the questionnaire given to the patients is shown in Additional file 1.

Three hundred ninety-five patients participated in the study. Twenty-five did not respond to all ABQ-HIV questions. Therefore, finally, the data of 370 patients could be included in all validation analyses. Patients who were excluded from the analysis due to missing ABQ-HIV data were on average 4.6 years older $(p=0.031)$ and more likely to be female $(15.7 \%$ vs. $20.0 \%, p<.001)$ than those who completed the ABQ-HIV (Table 1).

In the validation cohort of 370 patients, the mean age was 51.2 years. $15.7 \%$ were female (Table 1), the mean duration of known HIV infection was 11.7 years, and the mean time since commencement of ART was 8.7 years. Most common treatment regimens were tenofoviralafenamide/ emtricitabine/ elvitegravir (17.6\%), lamivudine/ abacavir/ dolutegravir (15.7\%), tenofoviralafenamide/ emtricitabine/ rilpivirine (11.4\%), and tenofovirdisoproxil/ emtricitabine/ efavirenz (11.1\%), which are all single-tablet regimens.

\section{Item properties}

Most of the items show a right-skewed distribution of the scores. The only exception was item 9 ("Generally, I find it unpleasant when other people notice my medication intake.") with a skewness of -0.16 . This item showed also the highest values for the mean (2.64) and the median (3.0).

Missing data analysis for specific items showed an outstanding value for item 11 ("Generally, I often feel bad, and sometimes I feel discouraged and depressed."), with a missing answer in 12 cases in comparison to all other items with a maximum of three to six missing answers. However, item 11 refers to a depressed mood which may be regarded a very personal and sensitive issue for which a higher risk of non-response was expected. Therefore, we decided not to exclude this item.

In item 3 ("I trust my doctor and agree on my therapy plan together with him."), and 4 ("My medications only help me if I take them on a strict regular basis."), more than $90 \%$ of participants "strongly agreed". As this suggested a ceiling effect, excluding these items was intensively discussed. Finally, we decided to keep them as they showed an acceptable item-total correlation, and since their exclusion would lead to a reduction of Cronbach's $\alpha$. 
Table 1 Baseline characteristics of patients

\begin{tabular}{|c|c|c|c|}
\hline Variables & $\begin{array}{l}\text { HIV patients who completed } \\
\text { the ABQ-HIV }\end{array}$ & $\begin{array}{l}\text { HIV patients who did not } \\
\text { complete the ABQ-HIV }\end{array}$ & $P$-values \\
\hline$N$ & 370 & 25 & \\
\hline Age in years - mean (SD) & $51.2(1.0)$ & $55.8(15.5)$ & 0.031 \\
\hline Female gender $-n(\%)$ & $58(15.7 \%)$ & $5(20.0 \%)$ & $<0.001$ \\
\hline Duration since first HIV diagnosis in years - mean (SD) & $11.7(0.3)$ & $10.3(6.1)$ & 0.466 \\
\hline Duration since first HIV treatment in years - mean (SD) & $8.7(0.2)$ & $8.6(5.7)$ & 0.829 \\
\hline Country of origin $-n(\%)$ & & & 0.464 \\
\hline Germany & $326(88.1 \%)$ & $21(84.0 \%)$ & \\
\hline Other $^{a}$ & $41(11.1 \%)$ & $4(16.0 \%)$ & \\
\hline Not specified & $3(0.81 \%)$ & $0(0.0 \%)$ & \\
\hline Education level - $n(\%)$ & & & 0.622 \\
\hline No degree & $24(6.5 \%)$ & $3(12.0 \%)$ & \\
\hline Apprenticeship & $208(56.2 \%)$ & $17(68.0 \%)$ & \\
\hline High school degree & $42(11.4 \%)$ & $2(8.0 \%)$ & \\
\hline University degree & $87(23.5 \%)$ & $3(12.0 \%)$ & \\
\hline Other & $2(0.5 \%)$ & $0(0.0 \%)$ & \\
\hline Not specified & $4(1.1 \%)$ & $0(0.0 \%)$ & \\
\hline Employment status - $n(\%)$ & & & 0.167 \\
\hline Employed & $240(64.9 \%)$ & $14(56.0 \%)$ & \\
\hline Unemployed & $45(12.2 \%)$ & $1(4.0 \%)$ & \\
\hline Pensioner/other & $81(21.9 \%)$ & $10(40.0 \%)$ & \\
\hline Not specified & $2(0.5 \%)$ & $0(0.0 \%)$ & \\
\hline \multicolumn{4}{|l|}{ Most common treatment regimens $-n(\%)$} \\
\hline Tenofovir alafenamide + emtricitabine + elvitegravir & $65(17.6 \%)$ & $2(8.0 \%)$ & \\
\hline Lamivudine + abacavir + dolutegravir & $58(15.7 \%)$ & $4(16.0 \%)$ & \\
\hline Tenofovir alafenamide + emtricitabine + rilpivirine & $42(11.4 \%)$ & $0(0.0 \%)$ & \\
\hline Tenofovir disoproxil + emtricitabine + efavirenz & $41(11.1 \%)$ & $2(8.0 \%)$ & \\
\hline $\begin{array}{l}\text { Number of tablets patients needed to take per day } \\
\text { (reported by the patient) }-n(\%)\end{array}$ & & & 0.906 \\
\hline Not specified & $6(1.6 \%)$ & $2(8.0 \%)$ & \\
\hline $1-3$ & $237(64.1 \%)$ & $14(56.0 \%)$ & \\
\hline $3-5$ & 67 (18.1\%) & $4(16.0 \%)$ & \\
\hline $5-10$ & 60 (16.2\%) & $5(20.0 \%)$ & \\
\hline
\end{tabular}

aBenin, Brazil, Bulgaria, China, Dominican Republic, France, India, Indonesia, Italy, Kameron, Kazakhstan, Kenya, Lebanon, Austria, Philippines, Poland, Portugal, Russia, Zambia, Tanzania, Thailand, Czech Republic, Turkey, Ukraine, USA

Furthermore, these items seemed to be associated with a socially desirable response behavior.

\section{Reliability}

The results of the reliability analysis are shown in Table 2. This analysis, based on all 17 initially included items, showed a Cronbach's $\alpha$ of 0.708 . The item-total correlations ranged from 0.120 to 0.488 , whereas item 14 ("family support") and item 16 ("consultation of the physician in case of side effects") showed the lowest values. The assessment of Cronbach's $\alpha$ after exclusion of these items confirmed that the reliability of the ABQ-HIV would be improved by removing both items. Thus, the questionnaire was reduced by eliminating item 14 and 16. Cronbach's $\alpha$ of the reduced 15-item scale was 0.720 . The calculation of a Spearman-Brown coefficient based on the reduced scale resulted in a split-half reliability of 0.724 , which was considered to be sufficiently high to confirm the internal consistency of the ABQ-HIV. 
Table 2 Reliability analysis

\begin{tabular}{|c|c|c|c|c|}
\hline \multirow[t]{2}{*}{ Item } & \multicolumn{2}{|c|}{$\begin{array}{l}\text { 17-item ABQ-HIV } \\
\text { (Cronbach's a: 0.708) }\end{array}$} & \multicolumn{2}{|c|}{$\begin{array}{l}\text { 15-item ABQ-HIV } \\
\text { (Cronbach's a: } 0.720 \text { ) }\end{array}$} \\
\hline & $\begin{array}{l}\text { Item-total } \\
\text { correlation } \\
\text { coefficient }\end{array}$ & $\begin{array}{l}\text { Cronbach's a } \\
\text { if item is } \\
\text { deleted }\end{array}$ & $\begin{array}{l}\text { Item-total } \\
\text { correlation } \\
\text { coefficient }\end{array}$ & $\begin{array}{l}\text { Cronbach's a } \\
\text { if item is } \\
\text { deleted }\end{array}$ \\
\hline $\begin{array}{l}\text { Item 1: "I fully understand what my doctor, } \\
\text { nurse or pharmacist has explained to me } \\
\text { regarding my medication therapy." }\end{array}$ & 0.291 & 0.701 & 0.289 & 0.715 \\
\hline $\begin{array}{l}\text { Item 2: "I can mention the names of my } \\
\text { medicines and their scope without hesitation." }\end{array}$ & 0.302 & 0.695 & 0.308 & 0.708 \\
\hline $\begin{array}{l}\text { Item 3: "I trust my doctor and agree on } \\
\text { my therapy plan together with him." }\end{array}$ & 0.254 & 0.704 & 0.228 & 0.718 \\
\hline $\begin{array}{l}\text { Item 4: "My medications only help me if I } \\
\text { take them on a strict regular basis." }\end{array}$ & 0.207 & 0.705 & 0.193 & 0.719 \\
\hline $\begin{array}{l}\text { Item 5: "Medicines are all poisonous. You } \\
\text { should avoid taking medicines at all if possible." }\end{array}$ & 0.352 & 0.689 & 0.364 & 0.702 \\
\hline $\begin{array}{l}\text { Item 6: "I feel basically healthy. Therefore, I } \\
\text { am sometimes unsure whether I really have } \\
\text { to take my medicines daily." }\end{array}$ & 0.273 & 0.699 & 0.286 & 0.712 \\
\hline $\begin{array}{l}\text { Item 7: "I take my medicines automatically } \\
\text { at a fixed time or on fixed occasions every } \\
\text { day (e.g. at meal times, before going to bed)." }\end{array}$ & 0.284 & 0.698 & 0.265 & 0.713 \\
\hline $\begin{array}{l}\text { Item 8: "I feel that co-payments for medication } \\
\text { are a great burden." }\end{array}$ & 0.370 & 0.687 & 0.399 & 0.697 \\
\hline $\begin{array}{l}\text { Item 9: "Generally, I find it unpleasant when } \\
\text { other people notice my medication intake." }\end{array}$ & 0.273 & 0.701 & 0.254 & 0.720 \\
\hline $\begin{array}{l}\text { Item 10: "I frequently forget things on a } \\
\text { daily basis." }\end{array}$ & 0.439 & 0.679 & 0.461 & 0.690 \\
\hline $\begin{array}{l}\text { Item 11: "Generally, I often feel bad, and } \\
\text { sometimes I feel discouraged and depressed." }\end{array}$ & 0.440 & 0.677 & 0.446 & 0.690 \\
\hline $\begin{array}{l}\text { Item 12: "I frequently have problems taking my } \\
\text { medications (e.g. swallowing, opening the } \\
\text { package, dividing the tablets) or it is difficult } \\
\text { for me to adhere to the accompanying conditions } \\
\text { of the medication intake (e.g. on an empty stomach, } \\
\text { with food or alcohol restrictions)." }\end{array}$ & 0.437 & 0.682 & 0.440 & 0.694 \\
\hline $\begin{array}{l}\text { Item 13: "I have difficulties adhering to my treatment } \\
\text { plan, especially when I am away from home (e.g. at } \\
\text { weekends, on business trips or holidays)." }\end{array}$ & 0.488 & 0.676 & 0.461 & 0.691 \\
\hline $\begin{array}{l}\text { Item 14: "I receive great support from my family } \\
\text { members/friends, who I can talk to at any time } \\
\text { and ask for help." }\end{array}$ & 0.120 & 0.720 & - & - \\
\hline $\begin{array}{l}\text { Item 15: "I am really frightened about the side } \\
\text { effects of my medicines." }\end{array}$ & 0.376 & 0.686 & 0.387 & 0.698 \\
\hline $\begin{array}{l}\text { Item 16: "In case I have already noticed or in case } \\
\text { I were to notice side effects related to my medicines: } \\
\text { I have talked or would talk to my doctor about them } \\
\text { as soon as possible." }\end{array}$ & 0.159 & 0.707 & - & - \\
\hline $\begin{array}{l}\text { Item 17: "In case I have already noticed or in case I } \\
\text { were to notice side effects related to my medicines: } \\
\text { I have stopped/would stop taking my medications } \\
\text { or took/would take less of them." }\end{array}$ & 0.189 & 0.706 & 0.199 & 0.720 \\
\hline
\end{tabular}

\section{Factor analysis}

Based on the reduced scale, factor analysis resulted in three different components of the questionnaire. The Eigenvalues of the components ranged from 1.314 to 3.313. Component 1 explained $22.1 \%$ of the variance and contained seven items (Table 3), which led to a subscale score ranging from 7 to 28 . Based on the content of the items loading on component 1 , this subscale represents the more unintentional barriers. Assuming that an unintentional adherence barrier exists if the item score is 
Table 3 Identified subscale by the means of factor analysis

\begin{tabular}{|c|c|c|c|}
\hline & $\begin{array}{l}\text { Component } 1 \\
\text { "Unintentional" }\end{array}$ & $\begin{array}{l}\text { Component } 2 \\
\text { "Knowledge" }\end{array}$ & $\begin{array}{l}\text { Component } 3 \\
\text { "Intentional" }\end{array}$ \\
\hline Eigenvalue & 3.313 & 1.329 & 1.314 \\
\hline Variance explained & $22.086 \%$ & $8.860 \%$ & $8.759 \%$ \\
\hline Possible range of subscale score & $7-28$ & $5-20$ & $3-12$ \\
\hline Observed range of subscale score & $7-27$ & $5-11$ & $3-12$ \\
\hline$N(\%)$ of patients with at least one barrier & $284(76.8 \%)$ & $38(10.3 \%)$ & $141(38.1 \%)$ \\
\hline \multicolumn{4}{|l|}{ Items } \\
\hline $\begin{array}{l}\text { Item 1: "I fully understand what my doctor, } \\
\text { nurse or pharmacist has explained to me } \\
\text { regarding my medication therapy." }\end{array}$ & & 0.642 & \\
\hline $\begin{array}{l}\text { Item 2: "I can mention the names of my } \\
\text { medicines and their scope without hesitation." }\end{array}$ & & 0.478 & \\
\hline $\begin{array}{l}\text { Item 3: "I trust my doctor and agree on my } \\
\text { therapy plan together with him." }\end{array}$ & & 0.696 & \\
\hline $\begin{array}{l}\text { Item 4: "My medications only help me if I } \\
\text { take them on a strict regular basis." }\end{array}$ & & 0.496 & \\
\hline $\begin{array}{l}\text { Item 5: "Medicines are all poisonous. You } \\
\text { should avoid taking medicines at all if possible." }\end{array}$ & & & 0.563 \\
\hline $\begin{array}{l}\text { Item 6: "I feel basically healthy. Therefore, I am } \\
\text { sometimes unsure whether I really have to take } \\
\text { my medicines daily." }\end{array}$ & & & 0.749 \\
\hline $\begin{array}{l}\text { Item 7: "I take my medicines automatically at a } \\
\text { fixed time or on fixed occasions every day (e.g. } \\
\text { at meal times, before going to bed)." }\end{array}$ & & 0.477 & \\
\hline $\begin{array}{l}\text { Item 8: "I feel that co-payments for medication } \\
\text { are a great burden." }\end{array}$ & 0.460 & & \\
\hline $\begin{array}{l}\text { Item 9: "Generally, I find it unpleasant when } \\
\text { other people notice my medication intake." }\end{array}$ & 0.554 & & \\
\hline Item 10: "I frequently forget things on a daily basis." & 0.613 & & \\
\hline $\begin{array}{l}\text { Item 11: "Generally, I often feel bad, and sometimes } \\
\text { I feel discouraged and depressed." }\end{array}$ & 0.651 & & \\
\hline $\begin{array}{l}\text { Item 12: "I frequently have problems taking my } \\
\text { medications (e.g. swallowing, opening the package, } \\
\text { dividing the tablets) or it is difficult for me to adhere } \\
\text { to the accompanying conditions of the medication } \\
\text { intake (e.g. on an empty stomach, with food or alcohol } \\
\text { restrictions)." }\end{array}$ & 0.568 & & \\
\hline $\begin{array}{l}\text { Item 13: "I have difficulties adhering to my treatment plan, } \\
\text { especially when I am away from home (e.g. at weekends, } \\
\text { on business trips or holidays)." }\end{array}$ & 0.468 & & \\
\hline $\begin{array}{l}\text { Item 15: "I am really frightened about the side effects } \\
\text { of my medicines." }\end{array}$ & 0.639 & & \\
\hline $\begin{array}{l}\text { Item 17: "In case I have already noticed or in case I were } \\
\text { to notice side effects related to my medicines: I have } \\
\text { stopped/would stop taking my medications or took/would } \\
\text { take less of them." }\end{array}$ & & & 0.693 \\
\hline
\end{tabular}

greater than two, $76.8 \%$ of the patients were affected by at least one unintentional barrier. The second component, which contains five items and accounted for $8.9 \%$ of the variance, can be labelled as subscale describing barriers associated with disease/treatment knowledge. The average score of this subscale (range: 5-20) was 5.9, and $10.3 \%$ of the patients reported to face at least one barrier within this subscale. Finally, item 5, item 6 and item 17 , which showed a maximum loading on the third component explaining $8.8 \%$ of the variance, can be labelled as intentional adherence barriers. The score of the intentional barriers subscale ranged from 3 to 12 ; the average score was 5.1 , and $38.1 \%$ of patients reported to be affected by at least one intentional barrier. 
Table 4 Convergent validity

\begin{tabular}{|c|c|c|c|c|}
\hline & ABQ total score of reduced scale & $\begin{array}{l}\text { Component } 1 \\
\text { "Unintentional" }\end{array}$ & $\begin{array}{l}\text { Component } 2 \\
\text { "Knowledge" }\end{array}$ & $\begin{array}{l}\text { Component } 3 \\
\text { "Intentional" }\end{array}$ \\
\hline $\begin{array}{l}\text { Correlation (p-value) with the total } \\
\text { score of MMAS -items }\end{array}$ & $-0.422(p<0.001)$ & $-0.396(p<0.001)$ & $-0.353(p<0.001)$ & $-0.171(0.001)$ \\
\hline \multicolumn{5}{|l|}{ Mean ABQ-HIV for patients ... } \\
\hline $\begin{array}{l}\text {... with at least medium adherence } \\
\text { (MMAS score }=>6 \text { ) }\end{array}$ & 24.01 & 13.27 & 5.76 & 4.97 \\
\hline $\begin{array}{l}\text {.... with low adherence (MMAS } \\
\text { score }<6 \text { ) }\end{array}$ & 29.60 & 17.00 & 6.84 & 5.65 \\
\hline$p$-value & $<0.001$ & $<0.001$ & $<0.001$ & 0.053 \\
\hline
\end{tabular}

a Use of the OMMAS is protected by US copyright laws. Permission for use is required. A license agreement is available from: Donald E. Morisky, SCD, ScM, MSPH,

Professor, Department of Community Health Sciences, UCLA School of Public Health, 650 Charles E. Young Drive South, Los Angeles, CA $90095-1772$

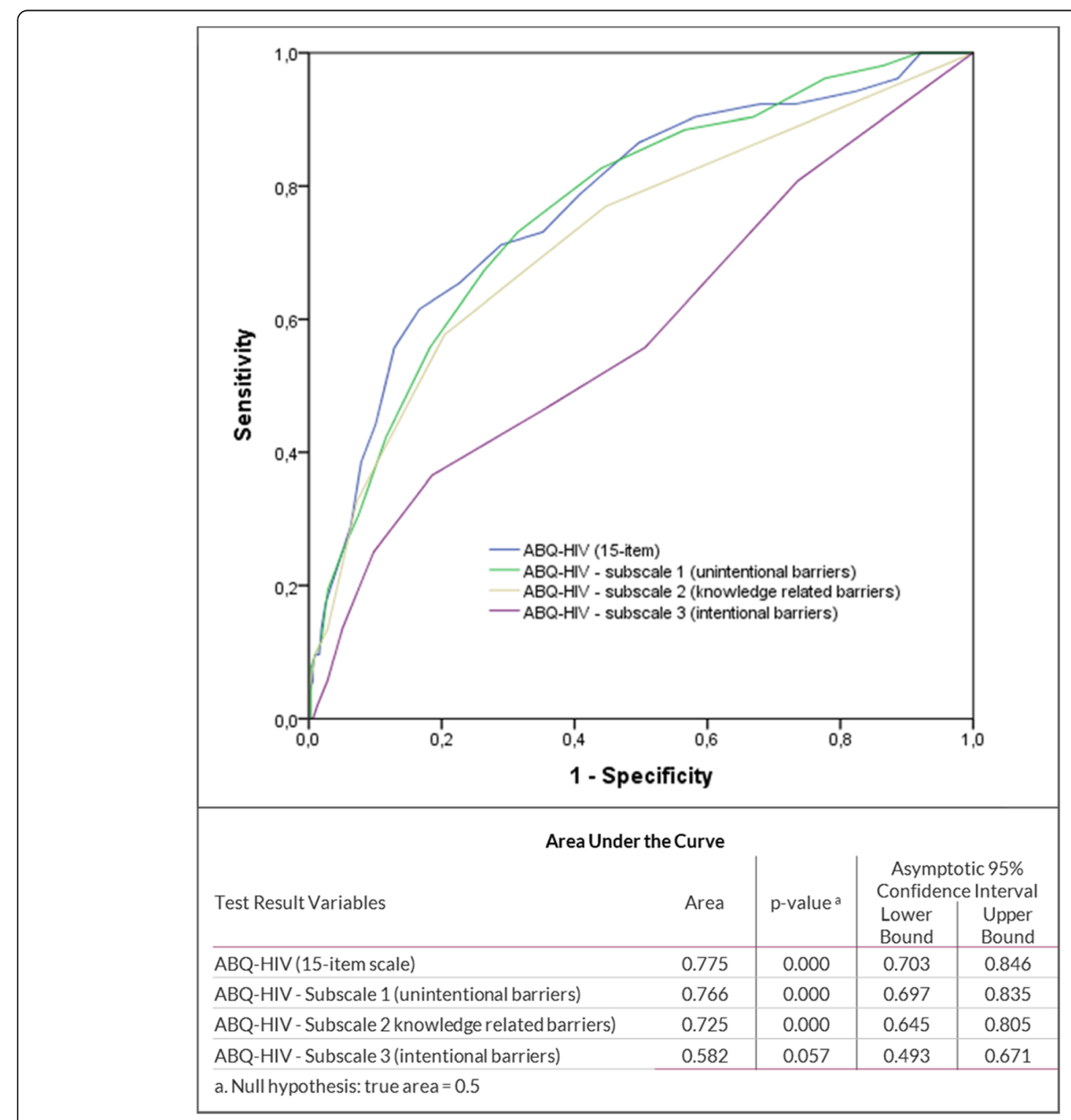

Fig. 1 Results of the ROC analysis 


\section{Convergent validity}

The convergent validity was tested using the MMAS as a self-reported adherence measure. It was possible to assess the MMAS score for 367 patients. The score of the reduced 15-item ABQ-HIV scale, as well as the scores of the three subscales, correlated significantly with the MMAS score (Table 4). All correlation coefficients were negative, indicating that a higher burden of adherence barriers measured by ABQ-HIV or its subscales was associated with a lower MMAS score and thus, with a lower adherence level. Furthermore, we evaluated the average ABQ-HIV score and the respective subscale scores in patients who showed low self-reported adherence (MMAS score $<6$ ), and compared their scores with the scores of patients with a minimum of medium adherence (MMAS score $\geq 6$ ). Patients reporting low adherence $(52$ of $367 ; 14.2 \%$ ) showed higher average scores for the ABQ-HIV and its affiliated subscales (Table 4).

The ROC curves for the overall ABQ-HIV scale and for the three subscales using the MMAS low adherence classification as state variable are shown in Fig. 1. The area under the curve $(\mathrm{AUC})$ was $0.775(p<0.001)$ for the ABQ-HIV 15-item scale, $0.766(\mathrm{p}<0.001)$ for subscale 1 (unintentional barriers), 0.725 for subscale 2 (knowledge related barriers), and $0.582(\mathrm{p}<0.001)$ for subscale 3 (intentional barriers). Based on the maximum value of the sum of sensitivity and specificity, the most suitable cut-off for the ABQ-HIV scale was identified. For the overall ABQ-HIV, a cut-off of $>28$ score value was identified (sensitivity: $61.5 \%$, specificity: $83.3 \%$ ). In our sample, 85 patients $(23.0 \%)$ reached a score of $>28$ and appeared to face a higher risk of facing substantial adherence barriers.

\section{Discussion}

The newly developed ABQ-HIV presented here displays reasonable psychometric properties. In order to identify adherence barriers, it can reliably and easily be applied to patients with HIV. Factor analysis provided three ABQ-HIV subscales, which refer to unintentional adherence barriers, knowledge related adherence barriers, and intentional adherence barriers. All subscales demonstrated significant correlations with the used adherence self-report instrument (MMAS-8๑). So, the ABQ-HIV can both be used as a tool to identify specific adherence barriers that may be present in an individual patient (use on an item-specific basis), as well as an instrument to identify certain adherence barriers clusters, which both facilitate the tailoring of adherence interventions.

No previous questionnaire focused on this issue in HIV. This validation study provided some new insights into the reasons for non-adherence in the treatment of HIV. It was observed that a high proportion of patients were affected by intentional adherence barriers. This is in contrast with other indications investigated. For example, the percentage of patients affected by intentional barriers was much lower in a sample of patients with atrial fibrillation [14]. In patients with atrial fibrillation, unintentional barriers were most common. This is also true for the investigated HIV sample, but the impact of depression/discouragement within this class of barriers was much higher than in patients with atrial fibrillation [14]. A similar impact of depression on the class of unintentional barriers could be observed in patients suffering from asthma [24]. Based on our results, a lack of information or knowledge seemed not to be a widespread problem in HIV patients.

We acknowledge some limitations to our study. This study was done with the help of a cohort of patients being taken care of by a group of infectious disease specialists in Hessia, Rhineland-Palatinate, and Saarland. Although outpatient clinics and private practices are located both in main and smaller cities, patients may neither be representative for the whole of Germany, nor for other European settings (e. g. out-of-pocket cost). So, it remains to be seen whether the ABQ-HIV shows similar properties when applied in other countries. Secondly, due to the cross-sectional design of the study, test-retest reliability and the ability to detect changes could not be assessed. Thirdly, even if the study sites were requested to include patients in a consecutive manner, there is a certain risk of a selection bias, since patients with more regular visits (and thus a better adherence behavior) were more likely to be overrepresented in the study. In addition, patients answered the questionnaire in the premises of the study site directly before or after a consultation with the treating physician. This responding environment might have increased the risk of a bias regarding socially desirable response behavior. Especially, for questionnaires containing sensitive and critical items, the compulsion to act in a socially desirable way could play a certain role. Thus, implementation of another scale like the Social Desirability Scale-17 [25] should be considered in future studies, in order to control for the tendency of respondents to answer in a manner that will be viewed favorably by health care providers (or others). Furthermore, although the ABQ-HIV was based on an existing, well-established instrument and the research team including clinical experts tried to cover all available evidence on NA causes in patients with HIV, there is a certain risk that the instrument does not cover all patient-relevant barriers. Future research is needed to fully prove the content validity of the ABQ-HIV and to assess whether the ABQ-HIV items can explain a reasonable part of existing non-adherence. Finally, we decided to use self-reported adherence to assess the convergent validity. Other measures to assess the adherence might be more powerful in validating our tool, e.g. data derived from medication event monitoring systems, but need much more resources.

In conclusion, the original $\mathrm{ABQ}$ could be successfully adapted for use by HIV patients. The developed ABQ-HIV is a practical, reliable, and valid instrument for identifying 
barriers to antiretroviral therapy adherence. The questionnaire has the potential to support physician-patient communication - knowing which kind of barriers might affect the patients would help clinicians and/or further stakeholders to approach specific issues with the patient. Although the ABQ-HIV might probably be not a measure that will be used by physician in clinical routine practice to "assess" individual patients' adherence, it is a tool that can be applied in patient collectives to generate awareness for patients' perspectives/barriers. Furthermore, in case adherence-promoting interventions are developed, the ABQ-HIV can be used as a tool to identify different patient clusters/segments and thus, to be able to implement interventions in a more specific / tailored way which would offer the possibility to enhance the effectiveness of adherence-supporting measures. Finally, future research is required to examine the usefulness of the ABQ-HIV in other settings and its ability to identify patient behavior changes over time.

\section{Additional file}

Additional file 1: Adherence Barriers Questionnaire for HIV (English) (DOCX $89 \mathrm{~kb}$ )

\section{Abbreviations}

ABO: Adherence Barriers Questionnaire; ART: Antiretroviral therapy; HIV: Human immunodeficiency virus; MMAS-8@: Morisky Medication Adherence Scale; NA: Non-adherence; ROC: Receiver operating characteristic; WHO: World Health Organization

\section{Acknowledgements}

Not applicable.

\section{Funding}

This work was not financially supported.

\section{Availability of data and materials}

The datasets generated and/or analyzed during the current study are not publicly available due to data protection guidelines.

\section{Authors' contributions \\ SM and TW developed the original $\mathrm{ABQ}$ and adapted the questionnaire together with JK (ABQ-HIV). SM has analyzed and interpreted the data together with VG. Furthermore, SM and VG were the major contributors in the writing of the manuscript. TW overlooked the scientific direction of the study and contributed to the writing of the manuscript. JK was leading the study. JK reviewed and revised the manuscript and interpreted the study results. Moreover, ME was responsible for the data collection, data validation and contributed to the interpretation of data and reviewing of the manuscript. All authors read and approved the final manuscript.}

\section{Ethics approval and consent to participate}

The study was approved by the independent Ethics Commissions of RhinelandPalatinate (837.077.16 (10396)), Hessia (121/2016), and Saarland (132/16), Germany.

\section{Consent for publication}

Not applicable.

\section{Competing interests}

Thomas Wilke has received honoraria from several pharmaceutical/ consultancy companies e.g. Novo Nordisk, Abbvie; Merck; GSK, BMS, LEO Pharma, Astra Zeneca, Bayer, Boehringer Ingelheim, Pharmerit.

\section{Publisher's Note}

Springer Nature remains neutral with regard to jurisdictional claims in published maps and institutional affiliations.

\section{Author details}

${ }^{1}$ Ingress-Health HWM GmbH, Wismar, Germany. ${ }^{2}$ Universitaetmedizin Mainz, Universitaetsmedizin, Germany. ${ }^{3}$ Klinikum Darmstadt, Universitaetsmedizin, Germany.

Received: 10 July 2018 Accepted: 19 November 2018

Published online: 28 November 2018

References

1. Osterberg L, Blaschke T. Adherence to medication. N Engl J Med. 2005; 353(5):487-97.

2. Haynes RB, Ackloo E, Sahota N, McDonald HP, Yao X. Interventions for enhancing medication adherence. Cochrane Database Syst Rev. 2008;(2): CD000011. https://doi.org/10.1002/14651858.CD000011.pub3.

3. Horne R, Weinman J, Barber N, Elliott R. Concordance, adherence and compliance in medicine taking. Rep Natl Co-ord Cent NHS Serv Deliv Organ R D. 2005:1-331.

4. DiMatteo MR. Variations in patients' adherence to medical recommendations: a quantitative review of 50 years of research. Med Care. 2004;42(3):200-9.

5. Bangsberg DR, et al. Non-adherence to highly active antiretroviral therapy predicts progression to AIDS. AIDS. 2001;15(9):1181-3.

6. Chesney $\mathrm{M}$ a. Factors affecting adherence to antiretroviral therapy. Clin Infect Dis. 2000;30(Suppl 2):S171-6.

7. Shukla M, Agarwal M, Singh JV, Tripathi AK, Srivastava AK, Singh VK. Nonadherence to antiretroviral therapy among people living with HIV/AIDS attending two tertiary care hospitals in district of northern India. Indian J Community Med. 2016;41(1):55-61.

8. Schaecher KL. The importance of treatment adherence in HIV. Am J Manag Care. 2013:19(12 SUPPL):S231-7.

9. Robbins RN, Spector AY, Mellins CA, Remien RH. Optimizing ART adherence: update for HIV treatment and prevention. Curr HIV/AIDS Rep. 2014;11(4):423-33.

10. WHO, "Adherence to long-term therapies; evidence for action," 2003.

11. Wilke T, Müller S, Morisky DE. Toward identifying the causes and combinations of causes increasing the risks of nonadherence to medical regimens: combined results of two German self-report surveys. Value Health. 2011;14(8):1092-100.

12. Odegard PS, Capoccia K. Medication taking and diabetes: a systematic review of the literature. Diabetes Educ. 2007;33(6):1014-29; discussion 1030-1031.

13. Mitchell AJ, Selmes T. Why don't patients take their medicine? Reasons and solutions in psychiatry. Adv Psychiatr Treat. 2007;13(5):336-46.

14. Muller $\mathrm{S}$, Wilke T. Validation of the adherence barriers questionnaire (ABQ)an instrument for identifying potential risk factors associated with medication-related non-adherence. Value Health. 2014;17(7):A512.

15. Morisky DE, Ang A, Krousel-Wood M, Ward HJ. Predictive validity of a medication adherence measure in an outpatient setting. J Clin Hypertens (Greenwich). 2008;10(5):348-54

16. Krousel-Wood M, Islam T, Webber LS, Re R, Morisky DE, Muntner P. New medication adherence scale versus pharmacy fill rates in hypertensive seniors. Am J Manag Care. 2009;15(1):59-66.

17. Morisky DE, DiMatteo MR. Improving the measurement of self-reported medication nonadherence: response to authors. J Clin Epidemiol. 2011;64(3):255-63.

18. Wójcik K, Piekarska A, Jabłonowska E. Adherence to antiviral therapy in HIV or HBV-infected patients. Przegląd Epidemiol. 2016;70(1):27-32, 115-8.

19. Stirratt MJ, et al. Self-report measures of medication adherence behavior: recommendations on optimal use. Transl Behav Med. 2015;5(4):470-82.

20. Streiner DL, Norman GR, Cairney J. Health measurement scales: a practical guide to their development and use. USA: Oxford University Press; 2015.

21. Clark LA, Watson D. Constructing validity: basic issues in objective scale development. Psychol Assess. 1995;7(3):309-19.

22. Terwee $C B$, et al. Quality criteria were proposed for measurement properties of health status questionnaires. J Clin Epidemiol. 2007:60(1):34-42.

23. Rust J, Golombok S. Modern psychometrics: The science of psychological assessment. Routledge; 2014

24. Gottschalk F, Mueller S, Torka S, Unmuessig V, Wilke T. Therapy adherence in asthma assessment of potential adherence barriers. Value Health. 2017;20(9):A647.

25. Tran US, Stieger S, Voracek M. Psychometric analysis of Stöber's social desirability scale (SDS-17): an item response theory perspective. Psychol Rep. 2012;111(3):870-84. 